\title{
Low Levels of Zinc in Hair, Anorexia, Poor Growth, and Hypogeusia in Children
}

\author{
K. Michael Hambidge ${ }^{[58]}$, Garolyn Hambidge, Margaret Jagobs, and J. David Baum \\ Department of Pediatrics, University of Colorado Medical Center, Denver, Colorado, USA
}

\begin{abstract}
Extract
Concentrations of zinc in hair were determined for 338 apparently normal subjects living in Denver with ages ranging from 0-40 years. Mean concentrations of zinc in hair were: neonates (25) $174 \pm 8$ (1 SEM) ; 3 months-4 years (93) $88 \pm 5 ; 4-17$ years (132) $153 \pm 5$, and $17-40$ years (88) $180 \pm 4$. Ten children more than 4 years of age had levels of zinc in hair of less than $70 \mathrm{ppm}$. Seven of these ten children had a history of poor appetite and eight had heights on or below the 10th percentile; the high incidence of low growth percentiles was not explicable on a familial basis. Taste acuity was tested in six of these children, and five had evidence of objective hypogeusia. After supplementing the diet with small quantities of zinc, taste acuity was normalized in each of these children and levels of zinc in hair increased.
\end{abstract}

\section{Speculation}

The correlation between low levels of zinc in hair, anorexia, and low growth percentiles in these children indicates that poor appetite and growth, in addition to the hypogeusia, may have been attributable to zinc deficiency. The low mean concentration of zinc in hair of infants and children under 4 years of age indicates that stores of zinc in the body may be low in this age group.

\section{Introduction}

Zinc is an essential trace mineral in the nutrition of microorganisms [41], plants [45], and animals [49]. This element has been found to be an integral part of several metalloenzymes, including carbonic anhydrase, alkaline phosphatase, lactic dehydrogenase, and carboxypeptidase [34]; zinc is also required for metabolism of nucleic acids and synthesis of protein [20, 31, 37, $38,51]$. Since 1934 when zinc deficiency was first described in animals [49], and particularly since 1955 when zinc deficiency was reported to be responsible for parakeratosis in pigs [50], the effects of zinc deficiency have been described in a number of different animal species [1, 6, 21, 30, 32]. Anorexia and poor growth are prominent features of zinc deficiency in young animals $[26,31,38]$.
Human zinc deficiency occurs in Egypt [39, 40] and other Mid East countries [9], where it is associated with retardation of growth and failure of sexual maturation in adolescent males. In other countries, including the United States, there have been isolated reports of zinc deficiency complicating chronic illness [4] or malabsorption [27]. Pories et al. [36] have shown that oral supplementation with zinc accelerates healing of wounds in surgical patients, and Sandstead et al. [44] have demonstrated that, in the rat, a beneficial effect of such supplementation is observed only in the presence of a pre-existing zinc deficiency. Henkin and associates have reported recently that hypogeusia and dysgeusia are relatively common disorders in adults [15, 19], and that these abnormalities of taste can frequently be corrected with oral therapy with zinc [15, 
16, 19]; however, it is not known whether these patients had a pre-existing zinc deficiency [52].

Criteria for the diagnosis of human zinc deficiency have not been defined adequately. Levels of zinc in hair have been demonstrated to reflect dietary intake of zinc in several animal species [24, 25, 29, 33, 43], and have been reported to provide a good index of stores of zinc in the body [47]. Low concentrations of zinc in human hair have been observed in association with zinc deficiency in the Mid East [48]. The initial aim of this investigation was to determine the content of zinc in hair of apparently normal neonates, infants, children, and young adults who were living in Denver, Colorado. This was part of a more extensive evaluation of hair as a potential index of human trace mineral nutritional status [11-13]. After processing these initial analytical data, it was apparent that the population included a number of young children with exceptionally low levels of zinc in hair. Accordingly, further data have been obtained on these subjects, including growth percentiles and objective measurements of taste acuity. This report details results of initial measurements of zinc in hair and of further investigations on children with low levels of zinc in hair, together with the initial results of dietary supplementation with zinc.

\section{Materials and Methods}

The 338 subjects from whom samples of hair were collected were all apparently healthy Caucasians from upper or middle socioeconomic families living in Denver, Colorado, who had no history of chronic or recent illness or surgery. Samples of hair from neonates were collected in the nursery for normal neonates at Colorado General Hospital from subjects born at term, whose weight was appropriate for gestational age. With the exception of the neonates, subjects were entirely unselected with respect to height and weight. The distribution of sex was approximately equal in all age groups.

Samples of hair were collected from the suboccipital area of the head by cutting adjacent to the scalp with forged stainless steel barbers' scissors. None of these samples had been treated with dyes or bleaches prior to collection. The proximal ends of the samples of hair, usually within $2 \mathrm{~cm}$ of scalp, were used for analysis. The samples were washed sequentially in hexane, 95\% ethanol, and deionized water. They were then dried overnight at $110^{\circ}$ in an electric oven, allowed to cool, introduced into glass ashing boats, weighed, and ashed in oxygen plasma [54]. The ash was dissolved in situ with $1.5 \mathrm{~N} \mathrm{HCl}$; depending on the original weight of the sample further dilutions were made so that $10 \mu \mathrm{l}$ acid contained the ash from $0.1 \mathrm{mg}$ original hair. Tenmicroliter aliquots were then analyzed in triplicate spectrochemically [10]. The mean relative standard deviation for 20 aliquots from the same sample was $5 \%$.

Taste acuity was tested by a three drop forced choice dilution technique [17]. Five concentrations each of $\mathrm{NaCl}$, sucrose, urea, and $\mathrm{HCl}$, representing the four basic qualities of taste (salt, sweet, bitter, and sour), were used (Table I). Assessment of appetite and diet were based on histories obtained from mothers. Heights and weights were plotted on growth charts based on data compiled by the Harvard School of Public Health and Iowa Child Welfare Research Station.

\section{Concentrations of Zinc in Hair}

Mean levels of zinc in hair for normal neonates, infants, children of different ages, and young adults are presented in Figure 1. The concentrations of zinc for neonates (mean $=174 \mathrm{ppm}$ ) were closely comparable with concentrations of zinc for young adults, but levels declined during infancy to a mean of $74 \mathrm{ppm}$, and remained very low until children were 4 years of age. The decline in mean levels of zinc in hair during infancy was also observed with serial collections of hair during the first year of life (Table II). For further comparison, the subjects were divided arbitrarily into four groups: 25 neonates $[$ mean $=174 \pm 8 \mathrm{ppm}(1$ SEM)]; 93 infants and preschool children aged 3 months -4 years $($ mean $=88 \pm 5 \mathrm{ppm}) ; 132$ children and adolescents aged 4-17 years (mean $=153 \pm 5$ $\mathrm{ppm}$ ); and 88 young adults aged $17-40$ years ( $180 \pm 4$ $\mathrm{ppm})$. The frequency distribution of levels of zinc in hair for these four groups is demonstrated in Figure 2.

Ten of the children more than 4 years of age had levels of zinc in hair as low $(30-70 \mathrm{ppm})$ or lower $(<30$ ppm) than levels reported for Egyptian adolescents with symptomatic zinc deficiency [48]. Forty-two (45\%) of all infants and children less than 4 years of age had levels of zinc in hair less than $70 \mathrm{ppm}$ (Table III), including eight subjects with levels less than $30 \mathrm{ppm}$.

Table $I$. Concentrations of solutions used for studies of taste acuity

\begin{tabular}{lrrrrr}
\hline \multicolumn{1}{c}{ Solution } & \multicolumn{4}{c}{ Conc., mmole/liter } \\
\hline Sodium chloride & 30 & 60 & 90 & 150 & 300 \\
Sucrose & 15 & 30 & 60 & 150 & 300 \\
Urea & 120 & 150 & 300 & 500 & 1000 \\
Hydrochloric acid & 3 & 6 & 15 & 30 & 60 \\
\hline
\end{tabular}




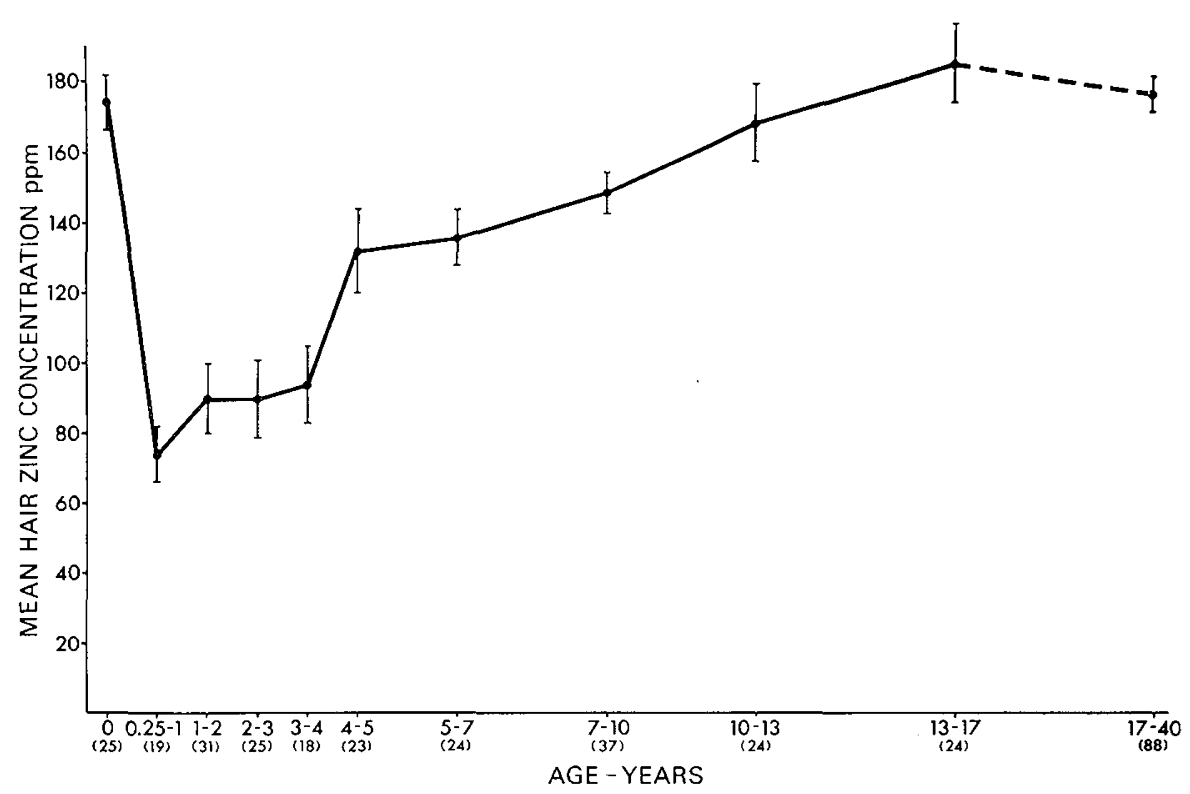

Fig. 1. Mean concentration of zinc in hair in subjects from $0-40$ years of age. Standard error of the mean indicated on graph. Number of subjects in each age group given in parentheses.

Table II. Changes in concentration of zinc in hair for same subjects during infancy

\begin{tabular}{lccc}
\hline \multirow{2}{*}{ Subject } & \multicolumn{3}{c}{ Hair zinc conc., ppm } \\
\cline { 2 - 4 } & Neonate & $5-8$ months & $9-12$ months \\
\hline$I$ & 161 & 44 & 31 \\
$I I$ & 170 & 48 & 58 \\
$I I I$ & 209 & 124 & 111 \\
$I V$ & 204 & 175 & 125 \\
$V$ & 173 & & 81 \\
$V I$ & 167 & & 46 \\
$V I I$ & 180 & & 107 \\
$V I I I$ & 194 & & 77 \\
\hline
\end{tabular}

\section{Growth and Appetite of Subjects with Low Levels of Zinc in Hair}

The age, sex, concentration of zinc in hair, and growth percentiles of children more than 4 years of age with levels of zinc in hair less than $70 \mathrm{ppm}$ are given in Table IV. Nine of these ten children had heights and/ or weights on or below the 10th percentile, including three who had heights and weights less than the 3rd percentile. Parents of eight of these nine children had heights and weights between the 25 th and 75 th percentiles with the exception of one mother whose height was between the 10th and 25th percentile; no data were available on the parents of subject 1. Seven of these children (subjects 2-5, 8-10) had a history of poor appetite. A correlation between low levels of zinc in hair, poor appetite, and low growth percentiles was

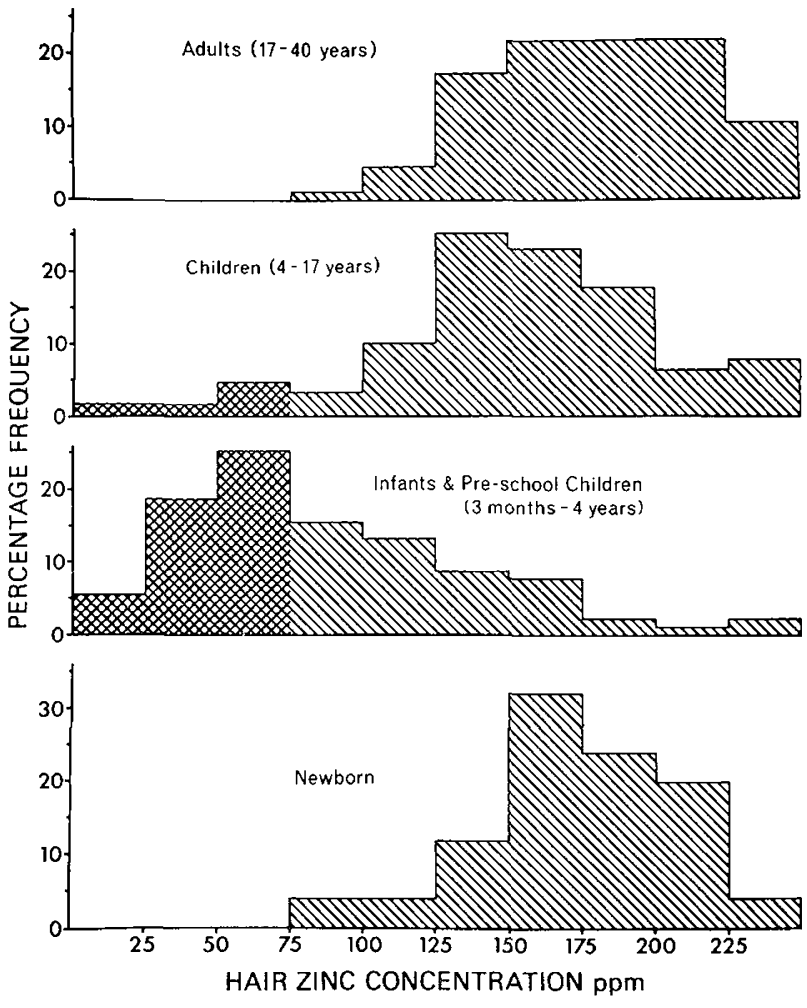

Fig. 2. Percentage of distribution of frequency of concentrations of zinc in hair (88 adults; 132 children aged 4-17 years; 93 subjects aged 3 months -4 years, and 25 neonates). Checkered area indicates percentage of subjects with levels of zinc in hair less than $75 \mathrm{ppm}$. 
Table III. Percentage of subjects with levels of zinc in hair $<30 \mathrm{ppm}$ and $30-70 \mathrm{ppm}$

\begin{tabular}{cccc}
\hline Age group & No. of samples & $<30 \mathrm{ppm}, \%$ & $30-70 \mathrm{ppm}, \%$ \\
\hline Neonate & 25 & 0 & 0 \\
3 months-4 yr & 93 & 8.6 & 36.6 \\
$4-17 \mathrm{yr}$ & 132 & 2.3 & 5.3 \\
$17-40 \mathrm{yr}$ & 88 & 0 & 0 \\
\hline
\end{tabular}

Table IV. Growth and taste acuity of children aged 4-16 years with levels of zinc in hair $<70 \mathrm{ppm}^{1}$

\begin{tabular}{|c|c|c|c|c|c|c|}
\hline \multirow{2}{*}{ Subject } & \multirow{2}{*}{$\begin{array}{c}\text { Age, } \\
\text { yr }\end{array}$} & \multirow{2}{*}{ Sex } & \multirow{2}{*}{$\begin{array}{l}\text { Hair } \\
\text { zinc, } \\
\text { ppm }\end{array}$} & \multicolumn{3}{|c|}{ Percentiles } \\
\hline & & & & Weight & Height & Hypogeusia \\
\hline 1 & 5 & $\mathrm{~F}$ & 10 & $<3$ rd & $<10$ th & + \\
\hline 2 & 7 & $M$ & 18 & $3 r d$ & 50 th & + \\
\hline 3 & 4 & $\mathrm{~F}$ & 27 & 10th & $3 r d$ & n.t. ${ }^{1}$ \\
\hline 4 & 7 & $\mathrm{~F}$ & 43 & $<3$ rd & $<3$ rd & + \\
\hline 5 & 5 & $F$ & 56 & 10 th & $<10$ th & + \\
\hline 6 & 7 & M & 58 & $75 \mathrm{th}$ & 75 th & n.t. \\
\hline 7 & 13 & M & 62 & $<10^{\text {th }}$ & $3 \mathrm{rd}$ & n.t. \\
\hline 8 & 6 & $M$ & 63 & $<3$ rd & $<3$ rd & + \\
\hline 9 & 5 & M & 64 & $<3 \mathrm{rd}$ & $<3 \mathrm{rd}$ & n.t. \\
\hline 10 & 5 & $\mathrm{M}$ & 67 & 25 th & 10 th & - \\
\hline
\end{tabular}

${ }^{1}$ n.t. : Not tested.

also observed in eight subjects less than 4 years of age with levels of zinc in hair less than $30 \mathrm{ppm}$. Six of these eight subjects had a history of poor appetite and had heights and/or weights on or below the 10th percentile. In each case percentiles had commenced to decline between 3 months and 2 years of age.

\section{Taste Acuity}

Each of 11 control children, aged 5-10 years, whose hair zinc concentrations were within the range for normal adults, had taste acuity within the range reported by Henkin et al. [17] for normal adults. In each case the most dilute solution (Table I) was detected as different from water and the second most dilute solution was recognized correctly; the most dilute solution was recognized correctly in $86 \%$ of tests. Taste acuity was tested in six of the children with low levels of zinc in hair, and there was evidence of objective hypogeusia in five cases, details of which are given in Table V. Subject 10 had normal taste acuity. Retesting following 1-9 months of dietary supplementation with zinc (1-2 $\mathrm{mg} \mathrm{ZnSO}_{4} / \mathrm{kg}$ body weight $/ 24 \mathrm{hr}$ ) revealed normal taste acuity in each of the five children who had objective hypogeusia (Table VI). Concentrations of zinc in hair for these children increased substantially within 2-4 months of the time therapy was commenced (Table VII).

\section{Discussion}

Zinc levels in human hair had been the subject of several reports $[3,23,28,35,42,46]$ and comments [8, $22,53]$ since the first documentation of low levels of zinc in hair of humans who were zinc deficient [48]; the potential advantages of this tissue as an index of the nutritional status of zinc have been re-emphasized recently [53], together with some of the problems in interpretation. The possible contribution of the external environment to zinc in hair content after adequate sample washing procedures has been controversial [2, 22, 35, 53]. However, unpublished observations in this laboratory, paralleling studies reported for chromium in hair [12], have demonstrated that the content of zinc in hair is not dependent on the time for which it has been exposed to the external environment in Denver; mean concentrations of zinc in hair for 30 subjects in

Table $V$. Taste thresholds of children with low levels of zinc in hair before dietary supplementation with zinc $^{1}$

\begin{tabular}{cccccc}
\hline \multirow{2}{*}{ Subject } & \multirow{2}{*}{\begin{tabular}{c} 
Age, \\
\cline { 3 - 6 }
\end{tabular}} & \multicolumn{4}{c}{ Taste thresholds, mmole/liter } \\
\cline { 3 - 6 } & & $\mathrm{NaCl}$ & Sucrose & Urea & $\mathrm{HCl}$ \\
\hline 1 & 5 & $30 / 60$ & $60 / 150$ & $300 / 500$ & $6 / 15$ \\
2 & 7 & $150 / \mathrm{NR}$ & $15 / 30$ & $120 / 150$ & $3 / 30$ \\
4 & 7 & $30 / 60$ & $30 / 60$ & $500 / 1000$ & $15 / 60$ \\
5 & 5 & $300 / \mathrm{NR}$ & $150 / 150$ & & $3 / 15$ \\
8 & 6 & $30 / 60$ & $30 / 60$ & $300 / 500$ & $3 / 6$ \\
\hline
\end{tabular}

${ }^{1}$ Numerator of each fraction $=$ detection threshold; denominator of each fraction = recognition threshold. NR: Not recognized in highest concentration.

Table VI. Taste thresholds of children with low levels of zinc in hair after dietary supplementation with zinc

\begin{tabular}{|c|c|c|c|c|c|c|}
\hline \multirow{2}{*}{ Subject } & \multirow{2}{*}{$\begin{array}{c}\text { Age, } \\
\mathrm{yr}\end{array}$} & \multirow{2}{*}{$\begin{array}{l}\text { Zinc } \\
\text { therapy, } \\
\text { months }\end{array}$} & \multicolumn{4}{|c|}{ Taste thresholds, mmole/liter } \\
\hline & & & $\mathrm{NaCl}$ & Sucrose & Urea & $\mathrm{HCl}$ \\
\hline 1 & 5 & 3 & $30 / 30$ & $15 / 15$ & $120 / 150$ & $3 / 3$ \\
\hline 2 & 7 & 1 & $30 / 30$ & $15 / 15$ & $120 / 120$ & $3 / 3$ \\
\hline 4 & 7 & 2 & $30 / 30$ & $15 / 15$ & $120 / 120$ & $3 / 3$ \\
\hline 5 & 5 & 3 & $60 / 60$ & $15 / 15$ & & $3 / 3$ \\
\hline 8 & 6 & 1 & $30 / 30$ & $15 / 15$ & $120 / 120$ & $3 / 3$ \\
\hline
\end{tabular}

Table VII. Increase in content of zinc in hair after dietary supplementation with zinc

\begin{tabular}{cccc}
\hline \multirow{2}{*}{ Subject } & \multirow{2}{*}{$\begin{array}{c}\text { Duration of } \\
\text { therapy, month }\end{array}$} & \multicolumn{2}{c}{ Hair zinc, ppm } \\
\cline { 3 - 4 } & 4 & Conc. & Increase \\
\hline 1 & 4 & 67 & 91 \\
2 & 4 & 112 & 49 \\
4 & 4 & 106 & 69 \\
5 & 2 & 170 & 107 \\
8 & & & \\
\hline
\end{tabular}


sections of the hair shaft immediately adjacent to the scalp did not differ significantly from concentrations in more distal sections of the same samples up to $30 \mathrm{~cm}$ distant from the scalp. This suggests that zinc in the external environment does not make a significant contribution to the hair zinc content. Further unpublished observations have confirmed Harrison's conclusions [14] that analytical results are not dependent on the choice of a wide selection of different washing procedures, including organic solvents or detergents. The variety of washing procedures employed by different investigators [14] does not, therefore, preclude meaningful comparison of results. In this study, the substantial increases in concentrations of zinc in hair observed following 2-4 months of dietary supplementation with zinc have provided further evidence [48] that levels of zinc in human hair reflect dietary intake of this element.

Concentrations of zinc in hair of less than $70 \mathrm{ppm}$ were associated with severe symptomatic deficiency of zinc in Egyptian adolescents [48], and were also $3 \mathrm{SD}$ or more below the mean for normal young adults in the present study. The occurrence of such low levels in 10 of 132 apparently normal children over the age of 4 years was unexpected, and suggested the possibility of zinc deficiency. Moreover, the correlation of low levels of zinc in hair with poor appetite and poor growth (the cardinal features of deficiency of zinc in young animals) in these children from an unselected population suggests that all three features may be attributable to low stores of zinc in the body. These data were obtained on an outpatient basis and no other investigations for short stature were included. However, the high incidence of relatively low growth percentiles was not explicable on a familial basis and medical histories revealed a possible cause for poor growth in only one child (subject 2) who had had a critical acute illness in early childhood.

Reports of poor appetite were supplemented by detailed nutritional histories from the mothers of five children. These were obtained retrospectively and have to be interpreted with caution. However, there were interesting similarities in these dietary histories; with one exception, the total daily caloric intake was only slightly below recommended intakes, but the variety of foods selected was limited. In particular, the consumption of meat was only 1 ounce or less per day despite the availability of greater quantities. Following the commencement of dietary supplementation with zinc, there has been a consistent improvement in appetite and dietary intake; in addition, there have been increases in rates of growth of four children. However, the possibility of a placebo effect cannot be excluded.

Recent advances in knowledge of normal and abnormal gustatory function $[15,16,18,19]$ indicate that zinc has a physiologic role in normal taste sensation; moreover, many cases of "idiopathic hypogeusia" in adults have been corrected by therapy with zinc [15, 19]. The observations of Henkin [52] suggested, but did not prove, that hypogeusia may be a feature of zinc deficiency unrecognized previously. In the present study, five of six children with low content of zinc in hair whose taste acuity was tested had evidence of objective hypogeusia, which was corrected rapidly following dietary supplementation with small quantities of zinc. This improvement cannot be attributed to placebo effect [15]. The impairment of taste acuity observed in children with low levels of zinc in hair, and the improvement which followed dietary supplementation with zinc, indicate that the hypogeusia was attributable to deficiency of zinc.

In the group of infants and children less than 4 years of age, a correlation between low levels of zinc in hair, anorexia, and poor growth was observed in subjects with concentrations of zinc in hair less than 30 ppm, but this correlation did not apply to the large number $(36 \%)$ of subjects of the same age with levels of zinc in hair between $30-70 \mathrm{ppm}$. On the basis of data obtained from Panama, Klevay has suggested that if zinc in hair is used as an index of zinc nutriture, only aged-matched individuals may be compared [23]. However, age-related differences in levels of zinc in hair of Panamanian subjects did not correlate with age-related differences observed in the present study. Indeed, Panamanian children less than 5 years of age had a higher mean level of zinc in hair than older Panamanian children; these levels were also much higher than that for subjects in the same age range living in Denver, and for infants elsewhere in the United States [46]. Adult levels in Denver and Panama were similar, indicating that differences observed in younger subjects are not attributable to different analytical techniques. Therefore, it appears that levels of zinc in hair are not directly related to age, and it is probable that levels at any age reflect zinc nutritional status. The exact relationship of content of zinc in human hair to stores of zinc in the body and zinc nutrition requires more precise definition before adequate interpretation of individual levels at any age can be achieved. In this study, eight of nine children more than 4 years of age with evidence of poor growth have had levels of zinc in hair less than $70 \mathrm{ppm}$ for at least 
I year, and the duration of a low level of zinc in hair may be as important as the absolute level. Certainly this is one possible explanation for the absence of a correlation between levels of zinc in hair in the range of $30-70 \mathrm{ppm}$ and possible features of overt deficiency of zinc in younger subjects.

Detailed investigations of metabolism, excretion, and balance of zinc were not undertaken in children with low levels of zinc in hair, and the explanation for these low levels has not been ascertained. Nutritional histories were retrospective and it was impossible to distinguish cause and effect of low content of zinc in the body. However, growth percentiles and appetite, even of the older group of children for whom retrospective information was available, declined between 3 months and 2 years of age; thus, if these features were attributable to zinc deficiency, the deficiency appears to have commenced in infancy. There is evidence that a substantial number of adults in the United States do not have optimal zinc nutriture [51, 52] and that the content of zinc in the average diet is not sufficient to guarantee an adequate intake at times of increased requirement [52]. Cavell and Widdowson [5] and Filer [7] have reported a negative balance of zinc in early postnatal life; no data on balance of zinc in older infants are available. However, nutritional requirements for zinc of the young, growing animal are relatively large, and it is probable that this applies equally to the human infant who may, therefore, be at particular risk from suboptimal zinc nutrition.

Previously reported cases of zinc deficiency in humans have been associated with factors such as: poor general nutrition [39], blood loss [39], excessive sweating [39], chronic infection [4, 39], malabsorption [27], and hospitalization and surgery [36]. Results of the present studies indicate that zinc deficiency may occur in otherwise normal children in this country. Moreover, levels of zinc in hair indicate that low stores of zinc in the body are common in infants and young children.

\section{References and Notes}

1. Barney, G. H., Macapinlac, M. P., Pearson, W. N., and DARBX, W. J.: Parakeratosis of the tongue-a unique histopathologic lesion in the zinc deficient squirrel monkey. $J$. Nutr., 93: 511 (1967).

2. BATE, L. C.: Adsorption and elution of trace elements on human hair. Int. J. Appl. Radiat. Isotop., 17: 417 (1966).

3. BRAdFIeld, R. B., YeE, T., ANd Baertl, J. M.: Hair zinc levels of Andean Indian children during protein-calorie malnutrition. Amer. J. Clin. Nutr., 22: 1349 (1969).
4. Caggtano, V., Schnitzler, R., Strauss, W., Baker, R. K., Carter, A. C., Josephison, A. S., and Wallack, S.: Zinc deficiency in a patient with retarded growth, hypogonadism, hypogammaglobulinemia and chronic infection. Amer. $J$. Med. Sci., 257: 305 (1969).

5. Cavell, P. A., AND Widdowson, E. M.: Intakes and excretions of iron, copper, and zinc in the neonatal period. Arch. Dis. Childhood, 39: 496 (1964).

6. Dynna, O., and Havre, G. N.: Interrelationship of zinc and copper in the nutrition of cattle: a complex zinc-copper deficiency. Acta Vet. Scand., 4: 197 (1963).

7. FILER, L. J.: Current problems in pediatric nutxition. Borden's Rev. Nutr. Res., 27: I (1966).

8. Flynn, A., Fratianne, R. B., Hill, O. A., Pories, W. J., and Strain, W. H.: Malversation in hair analyses. Amer. J. Clin. Nutr., 24: 893 (1971).

9. Halsted, J. A.: Human zinc deficiency. Trans. Amer. Clin. Clim. Ass., 82: 170 (1970).

10. HAmbrDGE, K. M.: Use of static argon atmosphere in emission spectrochemical determination of chromium in biological materials. Anal. Chem., 43: 103 (1971).

11. Hambidge, K. M., AND BAUM, J. D.: Hair chromium concentrations of human newborn and changes during infancy. Amer. J. Clin. Nutr., 25: 376 (1972).

12. Hambidge, K. M., Franklin, M. L., and Jacobs, M. A.: Changes in hair chromium concentrations with increasing distances from hair roots. Amer. J. Clin. Nutr., 25: 380 (1972).

13. Hambidge, K. M., Franklin, M. L., and Jacobs, M. A.: Hair chromium concentration: Effect of sample washing procedures and external environmental factors. Amer. J. Clin. Nutr., 25: 384 (1972).

14. Harrison, W. W., Yurachek, J. P., and Benson, C. A.: The determination of trace elements in human hair by atomic absorption spectroscopy. Clin. Chim. Acta, 23: 83 (1969).

15. HeNKIN, R. I.: Newer aspects of copper and zinc metabolism. In: W. Mertz and W. E. Cornatzer: Newer Trace Elements in Nutrition, p. 255. (MarceI Dekker, Inc., New York, 1971).

16. Henkin, R. I., and Bradley, D. F.: Hypogeusia corrected by $\mathrm{Ni}^{++}$and $\mathrm{Zn}^{++}$. Life Sci., 9: 701 (1970).

17. Henkin, R. I., Gill, J. R., And Bartter, F. C.: Studies on taste thresholds in normal man and in patients with adrenal cortical insufficiency: the role of adrenal cortical steroids and of serum sodium concentration. J. Clin. Invest., 42: 727 (1963).

18. Henkin, R. I., Graziadei, P. P. G., Bradley, D. F.: The molecular basis of taste and its disorders. Ann. Intern. Med., 71: 791 (1969).

19. Henkin, R. I., Schechter, P. J., Hoye, R., and Mattern, C. F. T.: Idiopathic hypogeusia with dysgeusia, hyposmia, and dysosmia: a new syndrome. J. Amer. Med. Ass., 217: 434 (I971).

20. Holt, A. B., Mellrts, E. D., ANd Cheek, D. B.: Comparisons between nucleic acids, protein, zinc, and manganese in rat liver: a relation between zinc and ribonucleic acid. Pediat. Res., 4: 157 (1970).

21. Hurley, L. S., and Swenerton, H.: Congenital malformations resulting from zinc deficiency in rats. Proc. Soc. Exp. Biol. Med., 123: 692 (1966).

22. Klevay, L. M.: Hair as a biopsy material. Amer. J. Clin. Nutr., 23: 377 (1970).

23. Klevay, L. M.: Hair as a biopsy material: assessment of zinc nutriture. Amer. J. Clin. Nutr., 23: 284 (1970). 
24. Lewis, P. K., Hoekstra, W., ANd Grummer, R. H.: Restricted calcium feeding during zinc supplementation for the control of parakeratosis in swine. J. Anim. Sci., 16: 578 (1957).

25. Macapinlac, M. P., Barney, G. H., Pearson, W., and Darby, W. J.: Production of zinc deficiency in the squirrel monkey (Saimiri sciureus). J. Nutr., 93: 499 (1967).

26. Macapinlac, M. P., Pearson, W. N., and Darby, W. J.: In: A. S. Prasad: Zinc Metabolism, p. 142. (Thomas, Springfield, IIl., 1966).

27. Mac Mahon, R. A., Parker, L. M., and McKinnon, M. C.: Zinc treatment in malabsorption. Med. J. Aust. 210 (1968).

28. McBean, L. D., Mahloudji, M., and Reinhold, J. G.: Correlation of zinc concentrations in human plasma and hair. Amer. J. Clin. Nutr., 24: 506 (1971).

29. Mreler, W. J., Powell, G. W., Pitrs, W. J., and Perkins, H. F.: Factors affecting zinc content of bovine hair. J. Dairy Sci., 48: 1091 (1965).

30. Mills, C. F., Dalgarno, A. C., Williams, R. B., and QuarterMAN, J.: Zinc deficiency and the zinc requirements of calves and lambs. Brit. J. Nutr., 21: 751 (1967).

3I. Mills, C. F., Quarterman, J., Chesters, J. K., Willuams, R. B., And Dalgarno, A. C.: Metabolic role of zinc. Amer. J. Clin. Nutr., 22: 1240 (1969).

32. O'Dell, B. L., Savage, J. E., and Newberne, P. M.: Significance of dietary zinc for the growing chicken. J. Nutr., 65: 503 (1958).

33. Ort, E. A., Smrth, W. H., Stob, M., And Beeson, W. M.: Zinc deficiency syndrome in the young lamb. J. Nutr., 82: 41 (1964).

34. Parisi, A. F., and Vallee, B. L.: Zinc metalloenzymes: characteristics and significance in biology and medicine. Amer. J. Clin. Nutr., 22: 1222 (1969).

35. Petering, H. G., Yeager, D. W., and Witherup, S. O.: Trace metal content of hair: zinc and copper content of human hair in relation to age and sex. Arch. Environ. Health 23: 202 (1971).

36. Pories, W. J., Henzel, J. H., Rob, C. G., and Strain, W. H.: Acceleration of wound healing in man with zinc sulphate given by mouth. Lancet, $i$ : 121 (1967).

37. Prasad, A. S.: Nutritional metabolic role of zinc. Fed. Proc., 26: 172 (1967).

38. Prasad, A. S.: A century of research on the metabolic role of zinc. Am. J. Clin. Nutr., 22: 1215 (1969).

39. Prasad, A. S., Halsted, J. A., and Nadurr, M.: Syndrome of iron deficiency anemia, hepatosplenomegaly, hypogonadism, dwarfism and geophagia. Amer. J. Med., 31: 532 (1961).

40. Prasad, A. S., Miale, A., Farid, Z., Sandstend, H. H., Schulert, A. R., AND Darby, W. J.: Biochemical studies on dwarfism, hypogonadism and anemia. Arch. Intern. Med., 111: 407 (1963).

41. Raulin, J.: Etudes cliniques sur la végétation. Ann. Sci. Nat. Bot. Biol. Vegetale, $11: 93$, (1869).

42. Reinhold, J. G., Kfoury, G. A., Ghalambor, M. A., And
BENNETr, J. C.: Zinc and copper concentrations in hair of Iranian villagers. Amer. J. Clin. Nutr., 18: 294 (1966).

43. Reinhold, J. G., Kfoury, G. A., ANd Thomas, T.: Zinc, copper and iron concentrations in hair and other tissucs: effects of Iow zinc and low protein intakes in rats. J. Nutr., 92: (1967).

44. Sandstead, H. H., Lanier, V. C., Shephard, G. H., and GrLlespre, D. D.: Zinc and wound healing: effects of zinc deficiency and zinc supplementation. Amer. J. Clin. Nutr., 23: $514(1970)$.

45. Sommer, A. L., and Lipman, C. B.: Evidence of the indispensable nature of zinc and boron for higher green plants. Plant Physiol., 1: 231 (1926).

46. Strain, W. H., Lascari, A., and Pories, W. J.: Zinc deficiency in babies. Proc. VII Int. Congr. Nutr., 5: 759 (1966).

47. Strain, W. H., Pories, W. J.: Zinc levels of hair as tools in zinc metabolism. In: A. S. Prasad: Zinc Metabolism, p. 363. (Thomas, Springfield, Ill., 1966).

48. Strain, W. H., Steadman, L. T., Lankau, C. A., Jr., Berliner, W. P., and Porres, W. J.: Analysis of zinc levels in hair for the diagnosis of zinc deficiency in man. J. Lab. Clin. Med., 68: $244(1966)$.

49. Tond, W. R., Elvefjem, C. A., and Hart, E. B.: Zinc in the nutrition of the rat. Amer. J. Physiol., 107: 146 (1934).

50. Tucker, H. F., and SAlmon, W. D.: Parakeratosis or zinc deficiency disease in the pig. Proc. Soc. Exp. Biol. Med., 88: $613(1955)$.

51. Underwood, E. J.: Trace Elements in Human anad Animal Nutrition. (Academic Press, New York, 1971).

52. Zinc in human Nutrition. Summary of Proceedings of a Workshop, National Academy of Sciences, Washington, D.C., December 4-5 (1970), p. 49.

53. Zinc in hair as a measure of zinc nutriture in human beings. Nutr. Rev., 28: 209 (1970).

54. Tracerlab, model 600L, Waltham, Mass.

55. The assistance of Mrs. JoAnn Curtis in preparation of this manuscript is gratefully acknowledged.

56. Presented in part at the Western Society of Pediatric Research, Carmel, Calif., February 3-4, 1972; and at the American Society of Clinical Nutrition, Atlantic City, N. J., April 29, 1972.

57. This work was supported by Agricultural Research Service, United States Department of Agriculture, Grant no. 12-14-1009941 (6I). Also supported in part by United States Public Health Service Grant no. R01-AM-12432 from NIAMD, and by Grant no. RR-69 from the General Clinical Research Centers Program of the Division of Research Resources, National Institutes of Health.

58. Requests for reprints should be addressed to: K. Michael Hambidge, M.D., Department of Pediatrics, Box 2741, University of Colorado Medical Center, Denver, Colo. 80220 (USA).

59. Accepted for publication August 15, 1972 . 